\title{
The Accounting Harmonization after the adoption of IAS's/IFRS's. The case of Greek and French Listed Companies
}

\author{
Vazakidis Athanasios $1^{\text {st }}$, Konstantinoudis Kleanthis $2^{\text {nd }}$
}

1 University of Macedonia, 156 Egnatia St., P.O. 1591, Thessaloniki, 54006, Greece, +302310891863

2 Technological Education Institute of Central Macedonia, Terma Magnisias, 62124, Serres, Greece, $+302321049175$

\begin{abstract}
Our methodology based on $\mathbf{H}$ index measurement, in order to determine if the adoption of IASs has increase the level of harmony. The sample constituted by Greek and French listed companies which are belonging to FTSE/ASE 40, and CAC 40, that have been adopt IAS's after mandatory adoption in 2005. Three accounting practices were included, depreciation, inventory and financial statement preparation. The results indicated that across the examined period 2013 - 2015, the majority of the $\mathbf{H}$ indices comparisons were positive and statistically significant for Greece. However, results for France indicates an almost totally disharmony.
\end{abstract}

Key Words: Accounting Harmonization, Accounting Policies

JEL Classification: M40, M41, M49

Corresponding Author: Konstantinoudis Kleanthis

\section{INTRODUCTION}

The necessity for channeling comparable and reliable financial information has been one of the objectives of internationalization of trade. For this reason, the adoption of a common accounting codification system was adopted through International Accounting Standards - International Financial Reporting Standards. The difference between the latter and the Generally Accepted Accounting Principles applicable in each country is of particular interest. Despite the fact that there are arguments about how we classify and measure the process of harmonization, there is an agreement as far as concerns: one procedure that raises the comparability of financial statements among different time frames and national borders.

The basic hypothesis of the analysis around harmonization is how the use of common account's practice between different firms will improve the degree of comparability between financial statements. (Van der Tas, 1988)

Nobes and Parker (2008) are in accordance with this opinion supporting that the harmonization as a procedure is something that lessen the alternative accounting policies and raises the homogeneity of accounting practices.

However, there are also researchers that argue with the change of national GAAP. More specifically, they disagree with the view that the quality of accounting should be reinforced, because of inherently differences into the international environment of financial information. According to this they support that the local GAAP better suits with the local business environment. This is obvious according to different cultures in which accounting standards developed (Doupnik T.S., 1995). Moreover, they 
support that IAS/IFRS are based on the principles that provide flexibility, which is driving, in some cases, to earnings manipulation. This resulting to reduce the accounting quality on users (Athianos et al, 2004).

Finally, Baker and Barbu (2007) on their study about the development of accounting harmonization consider that the right approach of the issue demands the attribution of: harmonization, normalization and standardization. Harmonization pursues to lessen the diversity of accounting choices so as to be more comparable. The creators' expectations in relation to the upcoming 'harmonization' can vary. Normalization is the term which is equally used with the term of standarization. This can have its roots in the English word «standard» that has been translated as 'norme' from the French language. As a consequence, the accepted meaning of the word standarization sometimes is misinterpreted as normalization. Owing to this misunderstanding in terminology, we define normalization as a term which stands between harmonization and standarization. On the stage of harmonization there are accounting rules, but they are not strict. As the procedure of I.A.H. continues, the rules are formed, leading in that way to a reduce in the numbers of accounting choices and consequently in a more standarised form. Tay and Parker $(1990,1992)$ claim normalization as «a movement to standarization ». Standarization in the procedure of I.A.H. is the period of uniformity or similar to uniformity. It is a stage which is characterized from bigger ambition. This derives from the fact that standarization adopts a unique group of accounting rules and practices that totally compliance with the rules are required. In standardization, the alternative choices are limited.

To sum up, all the accepted meanings agree with a wide variety of practices which are widely agile and vary towards total uniformity.

\section{MATERIALS AND METHODS}

\section{Types of Accounting Harmonization}

Accounting harmonization and the use of common practices in the way that the firms depicts financial statements constitutes a useful tool in order to provide entities useful and reliable information's to users. The deviation from a 'common accounting language' creates difficulties in the productivity of firms and especially multinational firms. On the other hand, external users such as investors, face difficulties to take investing decisions. Though the study of harmonization becomes easier dividing it in two categories: the real and the typical harmonization.

Real harmonization describes the accounting harmonization practices which are used in different firms. It is about the cohesion of the real application of rules.

Typical harmonization describes the harmonization of rules and practices. On a theoretical basis, provide the similarities and differences noticed in the accounting rules in different countries.

In literature, several researchers comment on the typical and empirical harmonization by using the terms 'dejure' and 'defacto' respectively.

However, Van der Tas (1988) differentiates the use of both terms. As de jure harmonization claims the whole of the rules and modifications determined by law and business union. On the contrary de facto harmonization includes practices as the introduced in their real application. Moreover, he adds that the typical harmonization is essential so as the real to succeed. Despite the fact that de jure harmonization cannot verify the existence of de facto, it is considered essential because without the legal limitation of alternative choices it cannot exist a significant harmonization of accounting practices.

Keeping in mind that the cause of international comparability of financial statements and the functional difficulty that there is in the process of measuring and evaluating harmonization, the most appropriate 
method for measuring seems to be the de facto harmonization. In this helps the great amount of studies that have grown around this subject throughout time. (Tay \& Parker, 1990, Athianos et. al, 2007)

\section{Literature Review}

\section{Literature review of harmonizing accounting practices}

Relative research on the use of accounting practices aim to reinforce the comparability of financial statements (Van der Tas, 1988). Harmonization is a procedure which correlates with the terms of normalization, standardization and uniformity. Standardization promote the uniformity of the financial statements and lead to a steadiness through formed rules. In addition, standardization, seems to be related with' the decline or the exclusion of choice' (Van der Tas, 1992). Finally, the harmonization of accounting practices is a matter that demands special approach (Athianos et al, 2005, Schuetze 1994, Goeltz 1991).

Archer, et al, (1996) apply two systymatical factors, the first is the national harmony and the related changes through time and the second is the disharmony inside countries, because of national differences in the choice of accounting policy. The results have shown a harmonization of a low level. McLeay, Neal, \& Tollington, 1999 studied harmonization and standardization separately giving a method for measuring harmonization that allows the use of alternative methods of accounting practice. Researchers prove that disharmony exists because of a systematic disharmony that local rules and practices are the only responsible.

Tower, Hancock, \& Taplin, 1999 due to the observed speed of IAS's that Australia has adopted in accordance with other countries, lead an investigation in six counties in Asia-Pacific. In a sample of 512 annual financial statements of listed firms have used multiple regression analysis and concluded in the outcome that local factors affect in a significant degree the rules of financial information. Floropoulos \& Moschidis, (2004) studied the readiness of small Greek firms in adopting IAS's IFRS's. The sample contained the answers of 70 accountants in a questionnaire of 14 questions in 2003. The results have shown the level of readiness of applying IAS's-IFRS's depends if the firm is listed or not, the size of the firm and the level of its activity. In addition, the size of firm depends on the qualifications of the accountant and his experience. There is no relationship between the statury of the firm (listed or not) and the level of the accountant's familiarisation with the application of IFRS.

Jaffar \& McLeay, (2007) studied the length of accounting harmony in Europe before the transition to IFRS, supposing that accounting methods harmonized with when «all the firms are active in the same business adopt the same accounting policy for the same transactions, regardless of their base». The factors which were examined are inventory, depreciation, goodwill and the chances of using alternative accounting methods. The empirical results show that international reports and the size of a firm are important factors to achieve harmonization. Finally, the effects of the environment of the country are bigger than the sectors which are not agree with harmonized accounting.

Moreover, Jinghan \& Peng, (2007) studied the Chinese policies adopted in an attempt to create fertile environment for the harmonization of domestic GAAP with IAS'S. The research reveals that reformation of a firm's management has no significant change in this direction. The action of Chinese accounting practice towards IAS'S-IFRS is owed especially of 2001 policy according to the abolishment of income gap. Researchers characterize the corporate governance as effective and point out that steps need to be taken not only from the government's side but also from the firms so as to succeed a healthy transition.

The relation between costs-benefit by adopting IAS'S in countries with different approaches on the subject of harmonization tried to study Taylor, (2009). The study is based on secondary data derived through financial statements. The sample constituted by 150 listed companies at random chosen 
(United Kingdom, Hong Kong and Singapore) for the first year of IAS's-IFRS's adoption. The results conclude that the size and the cost of the transition of financial statements in the U.K.are bigger than that of Hong Kong, while Singapore takes the third place. It is also reports that in these three countries the benefits for the users from the adoption of IAS'S, are insignificant in comparison with the value of the given information if it was used the domestic GAAP.

The study of Tan, Wang, \& Welker, (2011) examines the way that the harmonization of IAS'S affects the financial analysts. Throughout research we comprehend that the right adaptation of IAS's is an attraction for foreign analysts, who either use the same accounting standards, or have got previous experience, on that standards. Furthermore, the obligatory use of IAS's leads precisely to the estimations of foreign financial analysts. Researchers add that with the procedure of harmonization of accounting practices simultaneously exists an increase in the number of the local analysts who are experienced in the new accounting standards. Nevertheless, the foreseeable preciseness of the latter does not seem to affected directly by the use of IAS's. As a conclusion, the results show that accounting harmonization increase comparability that boost the usage of accounting standards.

Athianos, (2013) examines the impact of changes in accounting practices for Greece. Having separated the research in three parts analyses: The degree of harmonization of firms with the obligatory disclosures, as they are proposed in IAS's / IFRS's, concluded in an average degree of compliance at $90 \%$. The contingency of the value relevant that estimates the essential effect the book value and the net income, with important modifications in the value relevant of accounting information between 2004 and 2005. The degree of foreseeing the earnings from the financial analysts and the limitation of estimation earnings errors. He concludes a significant improvement in foreseeing the earning and the parallel decrease of errors.

Combs A, et, al (2014) study the cultural impact of harmonization of the Russian accounting practices with IAS'S. The results show a theoretical view of «Russian culture» which has got an impact in the Russian accounting practices with $\triangle \Pi Х \Pi$.

\section{Methodology and Data}

The data obtained through annual reports of sample firms. The sample constituted by companies were included in FTSE-ASE 40 index, listed in Athens Stock Exchange, as well as, French companies chosen were listed in CAC 40, listed in Paris Stock Exchange. Our observations span from 2013 to 2015. From the initial data gathering we exclude financial services firms. Consequently, the chosen business reflects an interdepartmental combination from trading and industrial companies which are affected not only from endogenous but also from exogenous factors, according to degree of extroversion of each company. As a result of the above the total sample of companies is 80 .

\section{Methodology}

In the accounting harmonization, the relevant variables are two. First, the number of the firms which use every accounting method and second the accounting method that have already been used.

More specifically, in this paper the index Herfindahl $(\mathrm{H})$ was used. The index $\mathrm{H}$ compares the relevant frequency of accounting methods which are used among firms of the same country of the examined sample. Index Herfindahl for a sample of firms is described as following:

$$
H=\sum_{I=1}^{N} p_{i}^{2}
$$


$\mathrm{H}=$ Herfindahl index.

$\mathrm{N}=$ number of accounting methods.

$\mathrm{P} i=$ Relevant frequency on the sample of accounting method

Index $\mathrm{H}$ varies between 0 (no harmony) and 1 (complete harmony) among the firms that use the same accounting method. The target of a country is to fulfil the perfect harmony, so as to acquire completely and rightly the directions of adoption that IAS'S impose. In a complete harmony, the whole of the firms converges to the same accounting method. This helps to allow data to be used and compared by both internal and external users. Except of the index $\mathrm{H}$, in literature exist index $\mathrm{C}$ and index I. Index $\mathrm{H}$ and index $\mathrm{C}$ provide harmonization measurements of accounting practices providing information on the frequency of use of the same accounting method or policy. Furthermore, index $\mathrm{H}$ is applied on a national level, whereas index-I measure the harmony on an international level. Index $\mathrm{C}$ is the ratio for the essential comparability of different accounting methods, including multiple reports and it is described as follows:

$$
C=\frac{a_{1} \bullet\left(a_{1}-1\right)+a_{2(}\left(a_{2}-1\right)-a_{12} \cdot\left(a_{12}-1\right)}{m \bullet(m-1)}
$$

$\mathrm{C}=$ harmonization index of each country

$\alpha_{1} \alpha_{1}, \alpha_{2} \alpha_{2}, \alpha_{1,2} \alpha_{1,2}=$ accounting reports

$\mathrm{m}=$ the number of countries under examination

Index I, as a different version of index $\mathrm{H}$, provides a correct schematic plan of the wideness and level of accounting harmonization among the countries, which is described as follows:

$$
I-I n d e x\left[\sum_{i=1}^{n}\left(f_{i}^{1} x f_{i}^{2} x \ldots x f_{i}^{m}\right)\right] 1 / m-1
$$

\footnotetext{
$f_{i=\text { relative frequency of method I in country }}$

$\mathrm{m}=$ number of countries

$\mathrm{n}=$ alternative number of accounting methods
}

A rising trend of index $\mathrm{H}$ will mean the improvement in level of harmonization, decreasing simultaneously the already used alternative accounting methods (the decrease of accounting alternatives is an important target for IASB, assuming in that way the level of harmonization increases). A high price for the index proves the right use of the standards, smooth operation of the edited mechanism and as well as use of financial information. On the contrary, a deceasing in the index will show a dis-harmony, in the sample of firms. This fact will mean that not progress was made and also that there is no success in the adoption of IAS'S / $\triangle \Pi X \Pi$ of the firms is not completely. Therefore, despite trying to succeed a decrease in the number of accounting practices, we face an increase, because the firms have multiple accounting choices. This can lead to a creative accounting and distortion of the real accounting results. In practice, the outcome will be connected to the management that using legally or illegally the combination of the accounting practices mislead users and especially, in larger disharmonies, affect the smooth function of financial and states mechanisms. 
Afterwards, a comparison of index $\mathrm{H}$ between the examined period and the year of first adoption of IAS will be made in order to verify if the adoption of accounting standards has led to a convergence of accounting practices, or the financial crisis, in Greece, has created a "relaxation" in the implementation of standards and mandatory disclosures from both business and audit mechanism. The examined variables focused on implementation of three basic accounting policies which are: the method of evaluating inventory, the method of choice of depreciation-amortization and the method of preparation of financial statements. According to IAS'S., for the preparation of financial reports of the firm the implemented method must be predefined. Especially for Greece according to the related laws and IAS's 2 the methods of measuring inventory include FIFO, Weighted Average and of Successive Balance. The basic depreciation-amortization methods, as defined in IAS 16 are the straight line and reducing balance. Finally, according to IAS 1, for the preparation of financial statements, the historical cost suggested as for initial recording of any transaction while fair values apply for the rest of useful life.

The use of alternative methods, which are not clarified through disclosures has led us to create an alternative option 'other methods' for all examined accounting policies. In addition, firms that do not disclosure any method, is taken into account as non-disclosure. That result affects the H-index as (nondisclosure) it is taken into account as accounting treatment and policy. We claim that, this creates a clearer result of how the accounting practices treated by the firms. As far as the study of French firms the alternative methods to measure inventories, depreciation-amortization and the preparation of financial statements vary. The influences from the Anglo-Saxon Accounting Model, as well as the different tax-business law, they give more choices to one of the categories under examination. The increase in alternatives creates a risk of altering the company's real situation through creative accounting and manipulation of the results.

For the study of each country we have created table for each one of these policies, including the following:

Methods of evaluating inventory: LIFO, FIFO, weighted average, successive balance, low price, other methods and non-disclosure

Depreciation - Amortization Methods: straight method, reducing balance, historic cost, market value, other methods and non-disclosure.

Reporting method of financial statements: costs basis, historic cost, other methods and non-disclosure.

\section{Results Analysis}

\section{Harmonization Degree in Greece}

The measurement of inventory includes five different methods. These methods are LIFO, FIFO, weighted average, successive balance, and other methods which are not acceptable from the tax authorities and the category of non-disclosures. We found that the majority of the firms $(76 \%)$ uses the method of weighed average cost, $11 \%$ implement FIFO and the $13 \%$ does not disclose any method. However, the method of successive balance was not an option. After that the level of harmony-index $\mathrm{H}$ equals to $0,6066=60,66 \%$.

It is clear that there is a preference for a particular method from the $3 / 4$ of the sample, but the objective is that the index $\mathrm{H}$ reaches 1 or very close to it so that we can speak of high harmony with the Standards. Moreover, $13 \%$ of firms not disclose any method, which raises interest in increasing the manipulation of results.

In addition, for 2014, 78\% of weighted average cost method applied, while the method of FIFO is applied only by $11 \%$, remaining at the same percentage as 2013 instead of non-disclosure which 
reduced by $2 \%$ in relation to 2013 , from $13 \%$ to $11 \%$. The rest of available methods there are no evidence of implementation. Index $\mathrm{H}$ is equals to $0,6325=63,25 \%$ improving level of harmonization by $3 \%$. This fact shows a convergence towards a method that, if continued, will lead to positive results for achieving harmony. Finally, for the year 2015 the evaluation methods of inventory introduce similar percentages with those of 2013. To be more specific, the $76 \%$ used the method of weighted average cost, $11 \%$ implement FIFO and the rest $13 \%$ of firms not disclose any method. The index $\mathrm{H}$ takes again the percentage of 0,6066 .

As regards the depreciation methods used by the sample companies, the straight-line method, the other methods and the non-disclosure were taken into account. The results are set at high harmonization rates as $99 \%$ of companies use the straight-line method, only one company does not disclose while the other methods, ie depreciations that are not clear how they are performed, are not observed. As a result of the above in 2013, index of harmonization in Greece comes at 0,9802 a fact that is connected with the high harmony and the rising probability of compare among the firms. Accordingly, in 2014 achieving a perfect level of harmonization, it scores 100\% in the straight-line method. Therefore, other methods and non-disclosure are of no value. As a result, index $\mathrm{H}$ is 1 . The high level of harmonization creates conditions of the improvement in flowing of information towards the external users of the financial statements. The same level of harmonization it is noticed through 2015 in a percentage of $100 \%$ for straight -line method. The rest of the alternatives, as it is obvious, keep zero percentage. Index $\mathrm{H}$ also equals to 1 , it as perfect harmonization.

Finally, in the measurement and preparation of the financial statements, we have taken into account the methods of historical cost, other methods and non-disclosure as options for treatment of the preparation of the financial statements. In 2013 the majority of firms in a percentage of $90 \%$ used the method of historic cost, the $10 \%$ did not disclosure any other method (i.e fair values), while no firm was included in the other methods. In 2013, the majority of enterprises with $90 \%$ used historical cost method, $10 \%$ did not disclose and no business was included in other methods. The $\mathrm{H}$ index, for the preparation of the financial statements, is 0.82 . It is fairly high price, but there is room for improvement. Regarding the 2014 notice that all companies do not show differences in relation to the corresponding year of 2013. The same companies used the same preparation methods, with $\mathrm{H}$ remaining at 0.82 . Finally, for $2015,92 \%$ prepared their financial reports according to the method of historical cost. Other methods were not observed in the sample and the companies that did not disclose fell to 8 . The $\mathrm{H}$ index was 0.8528 .

Table 1: Price index $H$ for Greece

\begin{tabular}{|c|c|c|c|}
\hline & $\mathbf{2 0 1 3}$ & $\mathbf{2 0 1 4}$ & $\mathbf{2 0 1 5}$ \\
\hline Inventory & 0,6066 & 0,6326 & 0,6066 \\
\hline Depreciation & 0,9802 & 1 & 1 \\
\hline Financial Statements & 0,8200 & 0,8200 & 0,8528 \\
\hline
\end{tabular}

\section{Harmonization degree in France}

In the 2013 inventory valuation method, we observe that the LIFO method of successive balance and low price, the rate is $0 \%$. $12.5 \%$ uses FIFO, only 30\% weighted average cost and 3\% for other methods. The above heterogeneity combined with $55 \%$ of the non-disclosure is a very worrying result about the validity of the information provided by the CAC 40 companies. The very low value of the $\mathrm{H}$ 
index is expected to be 0.4 . We find inconsistency in inventory valuation method and low control over the required disclosures.

Respectively for 2014, inventory valuation is accompanied by an increase in non-disclosure to $57.5 \%$. The weighted average cost was reduced to $25 \%$ but the FIFO increased to $15 \%$. The alternations between the methods are not significant and lead the index $\mathrm{H}$ back to 0.4 .

Finally, in 2015, the pattern of a high number of companies failing to disclose with $52.5 \%$ is repeated. From the methods disclosed, the weighted average cost increased only marginally to $27.5 \%$ while FIFO retained $15 \%$ of the previous year. $2.5 \%$ have other methods and market value. No improvement in inventory valuation has been observed, leading to the conclusion that companies generally have developed a profile of the methods they use and do not show any tendency to improve or align with the mandatory disclosures imposed by IAS's/IFRS's. The above results form the $\mathrm{H}$ index at 0.375 , significantly lower for inventories between years of the examined period.

As regards the depreciation methods observe respectively the same response. Specifically, in 2102, the high $47.5 \%$ of the non-disclosures combined with $37.5 \%$ of the straight-line method lead us to a similar conclusion as for inventories. Historical costs and other methods are $2.5 \%$, while the successive balance is nil. Finally, the market value is $10 \%$. The sample exhibits heterogeneity without a company's momentum in one method. The $\mathrm{H}$ index is 0.3775 and is particularly low. It is clear that non-disclosures to such a high degree are causing domino effects across the spectrum of users and investors in particular.

The same trend is postponed in 2014. The non-disclosure reaches $50 \%$, followed by the straight-line method with $25 \%$. 10\% do not disclose the accounting method, $7.5 \%$ apply the market value method and historical cost. As a result, the reduction of the $\mathrm{H}$ index to 0.3337 is quite discouraging. Finally, for 2015 , the straight-line depreciation method is increasing to $27 \%$. However, taking into account the increase in non-disclosure to 55\% is not a positive sample. $12.5 \%$ of companies are use other methods and only 5\% use market value. Hence the $\mathrm{H}$ index is equals to 0.3965 , where it is higher than the previous year, but the increase is not significant and the price is considered to be particularly low. Subsequently, the measurement of the preparation of the financial statements in 2013 points to nondisclosure to $45 \%$, following the high prices they presented above. The selected methods of the disclosure were historical costs of $32.5 \%$ and $20 \%$ on cost basis. With nearly half of the companies not disclosing and the others not using the same method, the H index is 0.1465 . However, in 2014 there is a further decrease in the $\mathrm{H}$ index $(\mathrm{H}$ index $=9 \%)$, as $57.5 \%$ does not disclose, $22.5 \%$ relates to historical costs and $20 \%$ relates to the cost base. Concluding the analysis, in 2015 , we notice that 47.5\% did not disclose, $22.5 \%$ used the cost-base method and the remaining $30 \%$ prepare financial statements according to historical cost. The $\mathrm{H}$ index is 0.14 , expected value, based on the diversity of percentages.

Table2: Prices of index $\mathrm{H}$ in France

\begin{tabular}{|c|c|c|c|}
\hline & $\mathbf{2 0 1 3}$ & $\mathbf{2 0 1 4}$ & $\mathbf{2 0 1 4}$ \\
\hline Inventory & 0,4 & 0,4 & 0,375 \\
\hline Depreciation & 0,3775 & 0,3337 & 0,3965 \\
\hline Financial Statements & 0,1465 & 0,0906 & 0,1406 \\
\hline
\end{tabular}

In summary, $\mathrm{H}$-values are particularly low. Three-year fluctuations are observed, not allowing safe conclusions to be drawn. The absence of a preferred method coupled with the particularly high rates of 
non-disclosure is related to the enforcement of IAS by businesses, creating a difficulty in understanding, analyzing and comparing for investors and users.

\section{Comparing price through transition in the present for the Greek Market}

Based on Athianos S. (2013) a research for Greece, in 2005 the $72.76 \%$ of all listed companies used the weighted average as a valuation method for inventories. Other methods were followed by $9.68 \%$, FIFO by $9.32 \%$ and non-disclosures by $7.89 \%$. Successive balance method achieves the lowest percentage, $0.36 \%$. This result is due to the fact that alternatives this year were more (in line with those considered for France).

Table 3: Inventories Measurement Methods 2004-2005-2015

\begin{tabular}{|c|c|c|c|}
\hline & $\mathbf{2 0 0 4}$ & $\mathbf{2 0 0 5}$ & $\mathbf{2 0 1 5}$ \\
\hline LIFO & $0,37 \%$ & - & - \\
\hline FIFO & $12,59 \%$ & $9,32 \%$ & $11 \%$ \\
\hline Weighted Average & $42,59 \%$ & $72,76 \%$ & $76 \%$ \\
\hline Successive Balance & $0,74 \%$ & $0,36 \%$ & $0 \%$ \\
\hline Lowest Price & $5,93 \%$ & - & - \\
\hline Other methods & $10,37 \%$ & $9,68 \%$ & $0 \%$ \\
\hline Non Disclosure & $27,41 \%$ & $7,89 \%$ & $13 \%$ \\
\hline
\end{tabular}

We observe that the weighted average cost method is the basic choice of companies, but convergence towards it in the past years has increased by about three percentage points. The percentage of nondisclosures is higher than in 2005, indicating a need for control to achieve a proper flow of information to users. Regarding depreciation, the $97.85 \%$ used a straight-line method and only $1.08 \%$ did not disclose.

Table 4: Depreciation Methods 2004-2005-2015

\begin{tabular}{|c|c|c|c|}
\hline & $\mathbf{2 0 0 4}$ & $\mathbf{2 0 0 5}$ & $\mathbf{2 0 1 5}$ \\
\hline Straight Line & $0,74 \%$ & - & $100 \%$ \\
\hline Reducing Balance & $2,59 \%$ & $9,32 \%$ & $0 \%$ \\
\hline Stable Methods & $3,33 \%$ & $97,85 \%$ & - \\
\hline Historical Cost & $0,37 \%$ & - & - \\
\hline Market Value & $15,19 \%$ & - & - \\
\hline Other methods & $58,89 \%$ & $0 \%$ & $0 \%$ \\
\hline Non Disclosure & $18,89 \%$ & $1,08 \%$ & $0 \%$ \\
\hline
\end{tabular}

During the transition, it was found that the increased number of companies using different methods without clarifying exactly what, and the variety of use of the other methods changed radically. With a high percentage, companies depreciated on a straight-line basis, where for the year 2015 they reached $100 \%$. This leads to complete harmony and it is obvious that the adoption was accompanied by a correct depiction of depreciation by all the companies, which has been maintained so far.

In 2005, 92.47\% prepared the financial statements based on historic cost and only $7.43 \%$ did not disclose. The results were identified as identical to the previous one, based on the concentration of companies in the use of a method and of course due to the significant reduction of those who do not. 
Table 5: Financial Statements 2004-2005-2015

\begin{tabular}{|c|c|c|c|}
\hline & $\mathbf{2 0 0 4}$ & $\mathbf{2 0 0 5}$ & $\mathbf{2 0 1 5}$ \\
\hline Cost Base & $16,30 \%$ & $92,47 \%$ & $92 \%$ \\
\hline Historical Cost & $55,19 \%$ & - & - \\
\hline Other methods & $0 \%$ & $0 \%$ & $0 \%$ \\
\hline Non Disclosure & $28,52 \%$ & $7,43 \%$ & $8 \%$ \\
\hline
\end{tabular}

The preparation of financial statements after nine years of mandatory adoption of IAS's/IFRS's is unchanged and maintains a high degree of harmonization.

\section{CONCLUSION}

This research paper has been deliberately focused on the past three years where Greece is still in economic downturn. In this way, we can draw conclusions on the extent to which the crisis has affected the way in which the financial statements are prepared and handled. In addition, the study of an additional country provides comparability with respect to the level of harmonization between European countries.

Lastly, a comparison between a year before adoption, first implementation and last year use provides a guide to drawing conclusions on the course of business over time.

For Greece, harmonization with Accounting Standards as well as depreciation is perfect. The levels of non-disclosure that existed prior to adoption (18.89\%) have been fully eliminated. Businesses apply a common accounting policy by channeling similar information's to external users.

The level of non-disclosure on the method of preparation of financial statements from $28.52 \%$ before implementation has fallen to $8 \%$. Businesses tend to be aggregated on a cost-based method with rates above $90 \%$, result that have not changed since the first year of adoption of the IAS's/IFRS's. The Hindex is relatively high but for full harmonization required additional compliance by the firms.

Regarding inventory valuation, the dispersion of business between different methods was a long way forward. Since the first year of adoption, prices have improved but not at a sufficient level. The results have not changed much so far. H-index is in medium-scale and implies a need for better treatment of the rules provided by the new accounting regime.

In France, the overall results are not proportional to the target. The great diversity affects and pushes the H-index to very low levels. In particular, in the preparation of financial statements the value of the $\mathrm{H}$ index tends to 0 resulting in complete disharmony. The main conclusions are two. Firstly, the low harmonization ratio hinders the financial analysis on the part of investors, hampering the sound operation of the money market. Second and foremost, there is a significant degree of manipulation of the results by channeling incomplete or false information to users.

To summarize, in Greece the improvement after the adoption of the International Accounting Standards is clear. However, the same situation in 2005 and today is likely to be linked to the general economic and social situation within the country where it ultimately acts as a deterrent to improving and refining the harmonization effort. Therefore, we cannot ascertain precisely whether the adoption of IAS / IFRS is the only factor in creating a positive trend in selected accounting policies. The reduction of alternatives, led to the use of common accounting policy choices. On the other hand, compared with France where the legitimate provision of an increased number of choices does not drive businesses towards a harmonization of accounting policies. 


\section{REFERENCE}

[1] Archer, S. et.al (1996). "A statistical model of International Accounting Harmonization", Abacus, vol.32, No.1

[2] Athianos S, Mandilas A, Tsamis A, Akritidou E, (2004), "Evidence of IAS Treatment in selected financial statements based on the Greek Accounting Policies", Accounting and Finance in Transition, Vol 2, ISSN 1743-1999, ISBN 1-86166-204-1

[3] Athianos et al, (2005), "Financial Statement Effects of Adopting International Accounting Standards: The Case of Greece", 4th Conference of the Hellenic Finance and Accounting Association, Piraeus, Greece.

[4] Athianos, S., Vazakides, A., Arsenos, P. (2007), "The Accounting Harmonization After the Adoption of IAS's / IFRS's: The case of Greek Listed Companies", International Review of Applied Economics, Vol 2, pp $31-67$.

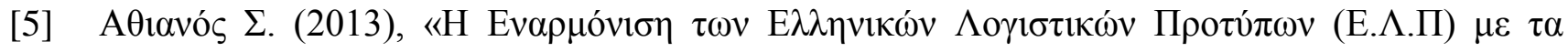

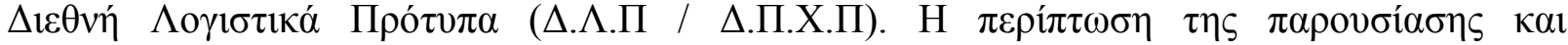

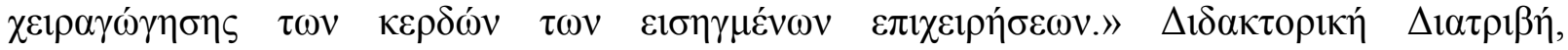

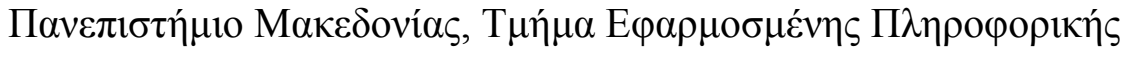

[6] Baker, R.C. and Barbu, E.M. (2007) "Trends in research on international accounting harmonization", International Journal of Accounting, vol. 42, pp. 272-304.

[7] Barth, M.E., Landsman, W.R., \& Lang, M., (2008). 'International accounting standards and accounting quality', Journal of Accounting Research, Vol. 46, No.3, pp. 467-498.

[8] Combs, Alan, Martin Samy, and Anastasia Myachina. "Cultural impact on the harmonisation of Russian Accounting Standards with the International Financial Reporting Standards: A practitioner's perspective." Journal of Accounting \& Organizational Change 9.1 (2014): 26-49.

[9] Doupnik, T.et.al. (1995). "External environment, culture and accounting practice: A preliminary test of a general model of International accounting development", International journal of Accounting, vol.30(3), pp.189-202.

[10] Emenyonu, E.N, Gray, S.J. (1996). "International Accounting Harmonization and the Major Developed Stock Market Countries: An Empirical Study", The International Journal of Accounting, vol.31, no.3, pp.26-279.

[11] Floropoulos, J. and Moschidis, O. (2004) "Are the small enterprises ready for the implementation of IFRS? The case of Greece", East-West Journal of Economics and Business, vol. 7, pp. 81-116. 
[12] Goeltz, R. K. 1991, 'International accounting harmonization: the impossible (and uncessary?) dream', Accounting Horizons, Vol. 5, No. 1 , pp. 85-88.

[13] Jaafar, A. et.al. (2007). "Country Effects and Sector Effects on the Harmonization of Accounting Policy Choice", Abacus, vol.43, no.2.

[14] Jean Jinghan, Chen, and Peng Cheng. "Corporate governance and the harmonisation of Chinese accounting practices with IFRS practices." Corporate Governance: An International Review15.2 (2007): 284-293.

[15] McLeay, S. et.al (1999). "International Standardization and Harmonization: a New Measurement Technique", Journal of International Financial Management and Accounting vol.10, pp.1.

[16] Nobes. C.W. (1998). "Towards a general model of the reasons for international differences in financial reporting", Abacus, vol.34(2), pp.162-185.

[17] Perramon, J. et.al. (2005). "IFRS Introduction And Its Effect On Listed Companies In Spain", University of Pompeu Fabra, Barcelona, www.ssrn.com.

[18] Rahman, A et.al. (1996). "Measurement of Formal Harmonization in Accounting: An Exploratory Study", Accounting and Business Research, vol.26, No.4, pp. 325-339.

[19] Schuetze W., 1994, What is the future of mutual recognition of financial statements and is comparability really necessary?, The European Accounting Review, 3 (2), 330-334

[20] Tan, Hongping, Shiheng Wang, and Michael Welker. "Analyst following and forecast accuracy after mandated IFRS adoptions." Journal of Accounting Research 49.5 (2011): 1307-1357.

[21] Taylor, Dennis W. "Costs-benefits of adoption of IFRSs in countries with different harmonization histories." Asian review of Accounting 17.1 (2009): 40-58.

[22] Tay, J.S.W, Parker, R.H. (1990). ““Measuring International Harmonization and Standardization", Abacus, vol.26, No. 1.

[23] Tay, J.S.W, Parker, R.H. (1992). ““'Measuring International Harmonization and Standardization: a Reply", Abacus, vol.28, No. 2.

[24] Tower, G. et.al (1999). "A regional study of listed companies' compliance with international accounting standards", American economic association, Quarterly, microform.

[25] Van Der Tas, L. G. (1988) . "Measuring of Harmonization of Financial Reporting Practice", Accounting and Business Research, vol.18, no. 70, pp. 157-169.

[26] Van Der Tas, L. G. (1992). "Measuring International Harmonization and Standardization: A Comment", Abacus, vol.28, No. 2. 